\title{
Engagement in Practice: Infusing the STEM Pipeline Through Community Engaged Learning
}

\section{Sara Jordan-Bloch, Clayman Institute for Gender Research at Stanford University}

Sara Jordan-Bloch is a sociologist and the Director of Leadership Research and Programs at the Clayman Institute for Gender Research at Stanford University. She is a core team member of the Voice \& Influence program, designed to help men and women be as effective as possible and create workplaces where all people can thrive. Jordan-Bloch also leads the Seeds of Change initiative, which aims to provide young women and girls with frameworks, knowledge, and skills to find and strengthen their own voice and to navigate critical transitions such as starting college and entering the workforce. Jordan-Bloch's scholarly research centers on the intersection of social psychology and education, and current projects include work on: the perception of mattering as a mechanism in teacher-student relationships, the relational context of cohort-based learning, and how gender inequality is experienced and understood during critical transitions for young women. Jordan-Bloch received her B.A. in sociology from Brown University and her Ph.D. in sociology from Stanford University.

\section{Ms. Shoshanah Cohen, Stanford University}

Shoshanah Cohen is the Director of Community Engaged Learning for Engineering at Stanford University. She holds a BS in Industrial Engineering from Stanford, an MA in Technology Strategy from Boston University, and an MBA from Harvard Business School. She has more than 20 years of industry experience managing complex supply chain projects; her teaching focuses on experiential project-based operations courses and community engagement. 
Engagement in Practice: Infusing the STEM Pipeline Through Community

Engaged Learning 


\begin{abstract}
This year, Stanford University's Clayman Institute for Gender Research launched a new initiative to address the glaring underrepresentation of girls and women in STEM-science, technology, engineering, and mathematics - fields. Motivated by the critical imperative of better understanding and addressing the gender biases that inhere early on in the STEM pipeline, this initiative aims to provide innovative training and support to young women in STEM as they transition through high school and college to successful technology careers. This initiative is distinct from traditional pipeline projects because it does not focus on the technical skills and education of STEM. Instead, the project takes an interdisciplinary approach to STEM education, infusing students' technical training with leadership training through a lens of gender inequality - bringing together key components of feminist pedagogy, community engaged learning, and experiential education to create a transformational learning experience. This is achieved by employing three core strategies: research-based education, a train-the-trainer model, and cohort-based learning. Our initiative launched this fall with approximately 100 participants: 17 undergraduate student leaders focusing on or interested in STEM, paired to co-lead 9 high school partner groups (each with 6-8 students). Our high school partnerships are with groups or organizations focused on STEM and vary in their context of socioeconomic advantage and learning setting (e.g., in-school and after-school). We are working in close partnership with Stanford's Community Engaged Learning program and the Haas Center for Public Service to build both an educational program and research agenda that emphasize the value of reciprocity, partnership, reflection, evaluation, and respect for diversity. In this paper, we present the lessons learned from our pilot year, including: the results from our feasibility evaluation, an assessment of our partnership model, and our approach to scaling. Assessment of the students and their progress is ongoing.
\end{abstract}

\title{
Project Background and Motivation
}

Underrepresentation of women in computer science and engineering fields is a persistent phenomenon. In the US, while women earn $53 \%$ of undergraduate bachelor's degrees overall, they represent only $18 \%$ of computer science graduates [1], [2]. Underrepresented minority women earn $6 \%$ of computer science degrees and $3 \%$ of engineering degrees [1]. Women represent $26 \%$ of computing occupations and only $12 \%$ of engineering occupations [3].

Even when women earn computer science and engineering degrees, they are less likely to persist in the field. Forty percent of women who earn engineering degrees opt for another occupation immediately after graduation or end up leaving the profession [4]. Women leave technology careers at much higher rates than do men [5], [6].

A self-reinforcing mechanism of underrepresentation is at fault. Persistent stereotypes of technology and engineering as male "geek" domains discourage girls from pursuing these areas of study [7][8]. Due to biased perceptions of competence, teachers, parents and peers are less likely to encourage women to choose technology careers. Girls are less likely to perceive themselves as technologists and as leaders. They are also less likely to believe they have the skills necessary to purse engineering and science careers even when they perform equally with boys. These lower self-assessments have been shown to reduce women's movement into engineering career paths [9], [10].

Women who do enter those careers report a lack of support and encouragement and are more likely to be encouraged to pursue managerial tracks over engineering-driven career paths, leaving them out of the development of technology and decreasing their opportunities for advancement into technical expert roles [11]. Women in engineering and computer science bachelors programs and in the workplace also report widespread isolation, which makes them more likely to leave the field, decreasing the number of role models and further reinforcing the stereotype of technology as a male field [3]. 
There are few pathways into engineering and an alarming rate of departure from the field, leaving girls systematically left out of the very careers that are their shaping their future.

\section{Project Design and Execution}

Our project-Seeds of Change-takes an interdisciplinary approach to STEM education, infusing students' technical training with leadership training through a lens of gender inequality - bringing together key components of feminist pedagogy, service learning, and experiential education to create a transformational learning experience. By planting a foundation of frameworks, knowledge, and skills, participants grow to not only recognize the dynamics of gender, but they also learn how to navigate environments so impacted by them. This is achieved by employing three core strategies: research-based education, a train-the-trainer model, and cohort-based learning.

RESEARCH-BASED EDUCATION. The Seeds of Change curriculum is grounded in academic research about how to effectively advance women's leadership and increase women's participation. This curriculum is brought to life in a series of animated videos designed by our researchers and curriculum designers, and put into action with the use of discussion guides and exercises to promote skills development. Topics include: Mindset, Persistence, Negotiation, Communication/Body Language, Feedback, Mentoring, and Purpose.

TRAIN-THE-TRAINER MODEL. Undergraduate students are trained in the core Seeds of Change curriculum and they, in turn, teach younger students this same curriculum. In their role as Leaders, the undergrads deepen their own knowledge and understanding of the core content, empowering their leadership in and beyond their role in Seeds of Change. For the high school students, learning from "near peers" just a few steps ahead of them provides access to relatable and attainable mentoring relationships.

COHORT-BASED LEARNING. In this model, the group is a critical mechanism for learning. By hearing about and sharing experiences, participants gain insight into their own circumstances and experience diverse leadership models. This approach breaks feelings of isolation and provides support and encouragement.

\section{Pilot Year: 2017-2018}

We launched the pilot year of Seeds of Change in the fall of 2017 with approximately 80 participants: 17 undergraduate student leaders focusing on or interested in STEM, paired to co-lead 9 high school partner groups (each with 6-8 students) ${ }^{1}$. Our high school partnerships are with groups or organizations focused on STEM and vary in their context of socioeconomic advantage and learning setting (e.g., in-school and after-school).

To participate as a Seeds of Change "leader", undergraduate students submitted an online application, participated in an in-person interview, and committed to enrolling in a one-unit per quarter course for the entire academic year. This course is designated by Stanford as a community engaged learning course, allowing interested students to have their participation count towards a University-endorsed community engaged learning transcript notation. Leaders attend a monthly training session and in the following month, each pair of co-leaders visits their high school site and trains their student group, or "circle". This staggered training approach ensures that materials are fresh and that the training approach can be adjusted to the needs of the students in real time.

\footnotetext{
${ }^{1}$ One of our Leaders leads two groups
} 
Leaders are required to complete a series of assignments both prior to and following the monthly training course and their high school group meetings. They are assigned book chapters, academic research articles, and educational videos relevant to the topic at hand, and they complete monthly reflections on how they are applying to leadership concepts they are learning (and teaching) to their own lives. Additionally, the undergraduate students serve as research assistants for the research component of this project, and they each complete field notes about their high school group meeting. While their time preparing for and attending the course is associated with course credit, their time in the field leading their high school groups is compensated with a small stipend.

The leader training meetings follow this structure (duration: 2 hours $15 \mathrm{~min}$ ):

- Check-In. Students get in small groups to share their progress applying their leadership frameworks and skills to their lives and STEM contexts.

- Reflect and Debrief: Previous Circle Meeting. Students reflect individually, in co-lead pairs, and with co-leaders from a different site about how their previous meeting went (i.e., what went well, what could have gone better, what improvements could be made). They are also encouraged to explore common themes they see from meeting to meeting and ways in which the different sites are having systematically similar (or different) experiences.

- Train: Upcoming Circle Meeting. Students are introduced to the materials they will be using to lead their upcoming high school circle meetings. They watch the relevant episode in the Seeds of Change animated video series and then break into small groups to engage in a conversation about the topic using the discussion guide they will be using with their circles. Students are encouraged to participate in the discussion through the lens of their own lives, and then they are given time to reflect on and plan for how they will lead this discussion in their high school circles.

- Closing. Leader training meetings end with each leader sharing one action she commits to doing before the next meeting to practice the newly introduced leadership framework or skill. Leaders are accountable for submitting written reflections about their progress at the end of the month and sharing their progress at the next month's check-in.

The high school groups follow a similar meeting structure, but without the focus on teaching. Key components include: Check In, Video, Discussion, and Closing. As with the leaders, the high school students are accountable for committing to and sharing about one action they will take to practice.

\section{Lessons Learned Through Successes or Failures}

In the following section, we highlight some lessons learned in the first few months of our pilot program and, in particular, as related to our two primary partner relationships - undergraduate students and high school groups.

\section{Undergraduate Student Leaders}

Unique Space. One emerging theme from our data is how distinct the spacephysical and curricular-our program occupies is for our students. Our meetings are held at the Clayman Institute, which is located in a repurposed house on campus. Our students experience this space as a contrast to the STEM spaces where they are learning during the day-spaces where many of our students describe feeling as if they do not fully belong. In addition to the physical space of the house, the gender composition of this space is also distinct from their other STEM contexts. Whereas many of our leaders describe being one of only a handful of women in their classes, Seeds of Change is a STEM environment where women are central. Additionally, students describe this space as providing unique opportunities to connect and share stories about their experiences in STEM. Our curriculum emphasizes the importance of vulnerability as central for resilience, and this approach to learning is again distinct from other STEM 
environments where the competitive culture does not make space for these kinds of connections to emerge. This allows leaders to normalize feelings that sometimes lead them to feel isolated and creates a space where they can feel validated and get support.

Learning Through Leading. The train-the-trainer model is intended to offer the leaders an enhanced learning experience through their role as instructors. The leaders, as both learners and teachers of the program's core content, deepen their own understanding of the content and have an opportunity to develop their leadership identities in STEM. After leading her first high school circle meeting, one student reflected:

"I worry that I may not be able to relate to them as much as I would like, but I hope that the girls enjoyed the program and will gain valuable tools that will aid in their transition from school to STEM fields. This meeting was also critical in revealing leadership areas in which I can improve, as I can now spend time thinking about how to make myself a more engaging leader so that the girls will participate more."

This program provides students with the opportunity to learn about leadership while simultaneously bringing their own leadership to life as they lead their high school circles. This is especially important for this population, as many of our students describe the feeling of being hesitant to step into leadership roles in their STEM classes and labs. For many of our leaders, this reluctance comes not from a lack of skill or experience, but rather from a feeling that their leadership is unwelcome. In addition to being a requirement of their role as "leader," our program's focus on teaching and mentoring-which is congruent with gender expectations - is a comfortable way into leadership. We look forward to deepening our understanding of how this process unfolds.

The Gender Lens. As curriculum designers and educators, one of our primary areas of inquiry in this work has to do with when/how to be explicit about the role of gender bias in this curriculum. We describe our curriculum as "leadership curriculum with a gender lens", meaning that all the topics we are teaching are areas where we know from research that: 1) knowing these frameworks and skills can enhance leadership and promote advancement, yet, because of expectations associated with gender, these topics are often missing from women's and girls' education and, 2) once learned, men and women have differential experiences engaging with these frameworks and skills due to the role of gender bias and gender stereotypes. We make the first point explicitly with our student leaders. The second point, however, is an area where we are uncertain how much to emphasize, for concern that we will be the "bearer of bad news" and scare the students - undergraduate and high school alike - off from the learning. We have prioritized this as an area of inquiry in our research and, through the data collected in student reflections and meeting field notes, we are paying close to attention to if/when/how all the program participants bring a gender lens to how they are understanding the material. We intend to use the data from this pilot year to better understand the balance necessary to promote a culture of learning that is both informative and empowering, and we will use these findings to inform our approach in the future.

\section{High School Groups}

Setting Matters. For this pilot year, we identified our high school sites mostly through our networks (e.g., stakeholders in our community, local organizations connected to Stanford, etc.). We had a 2x2 design in mind when we were forming our partnerships - we wanted to vary the context of socioeconomic advantage and we wanted to vary our in-school/out-of-school setting. We aimed to have at least one partnership in each quadrant. We were successful in forming partnerships in three out of four conditions - high context of advantage in-school setting, low context of advantage in-school setting, and high context of advantage out-of-school setting. We were unsuccessful, however in securing a site in a low context of advantage out-of-school setting. ${ }^{2}$ This left us with only one site-and only one circle

\footnotetext{
${ }^{2}$ We discuss some of the reasons for this in the section below
} 
group - in an out-of-school setting. For this reason, our emerging findings about the differences between settings are only suggestive and will require more investigation in the future. However, we are seeing some importance differences between how our program works in-school vs. out-of-school. The participants in our out-of-school setting are demonstrating a higher level of engagement in the program and are, importantly, more willing to share and connect with each other than the students in our in-school settings. Some of this is a selection story, as the participants in this setting have opted into being in the program from the context of another opt-in program. While our in-school participants have also opted into the program, they are doing so from the context of their school. In some of our in-school sites, teachers have recommended them for the program and they are participating during school time, which, while still their choice, feels much more like a requirement of school. Emerging findings suggest that, in this setting, students' approach to the program is more transactional and with less willingness to be vulnerable and connected. The most useful comparison has been when looking at our two settings where there is a high context of advantage. In many ways, these populations are quite similar. But, in the out-of-school setting the students seem to be much more free to share and are more open to learning together. In this setting, they are less accountable to being a certain way - they can try on new skills and perspectives with more freedom. As we continue to grow the program, we intend to focus partner recruitment efforts on out-ofschool settings to more future explore the constraints and opportunities that various learning settings provide. This seems especially important for this highly relational work.

Supporting Partnerships. As discussed above, we had some difficulty securing partnerships in a low context of advantage out-of-school setting. We had several meetings with interested and enthusiastic potential partners, but at the end of the day, their decision about whether to partner came down to a question of resources. While we tried to require very little of the adult stakeholder at each partner site, there are still several responsibilities that come with the partnership (e.g., identifying participants, sending and collecting parent consent forms, hosting monthly meetings at the site). Even though the time associated with playing this role is not extensive, it has to be accounted for. At our school settings, this role fit within the job of some teachers and they took it on without any additional compensation. This was true at both our low and high context of advantage settings. At our out-of-school setting, this role was taken on by an adult stakeholder who volunteers her time and who was willing and able to take on this extra commitment without compensation. At one of our high context of advantage school sites, the principal gave the teacher who took on this role a stipend to cover the time associated with this project. Moving forward, we will approach our partnerships with more knowledge of the exact time commitment and are working to have some resources available to support engagement (e.g., a needs-based grant) and to decrease the time commitment of the adult stakeholder (e.g., more streamlined processes to distribute materials and send reminders).

\section{Conclusions and Next Steps}

With a few more months to go in our pilot year and our pre-/post-evaluation not yet complete, we still have much to learn about our program. We have built a large, mixed-method longitudinal data set consisting of pre- and post-program interviews and surveys for all participants, as well as on-going assessments of the curriculum and meetings. We plan to iterate on the program based on our pilot year evaluation and roll it out again next academic year at our University.

With this work, a big question is about scalability. How do you increase the number of people who participate without losing the high-touch relational features of the program that are so central to its design? We have built much of the curriculum with scalability in mind (e.g., animated film series, discussion guides), with the idea that leaders could be trained and deployed without having to be at Stanford. But how do we effectively scale high school partner relationships from outside the local community? We are interested in exploring the idea of partnering with girl-serving STEM organizations that are working at regional or national levels to see how our programs could support each other. 
This project is currently funded by a grant that provided seed funding for research and development, through pilot. It has been a highly resourced project at a highly resourced university. But, if we are to scale this initiative, we will need to develop a model that either requires fewer resources (e.g., staff time, funds for leader transportation, etc.) or has resources built into it (e.g., centralized staffing, grants).

The Seeds of Change initiative is part of the Clayman Institute's broader mission of creating inclusive organizations where everyone can equally thrive. Whether we are working with companies to intervene in organizational processes where bias is embedded or teaching individuals about how to navigate critical life and leadership transitions, we believe that real, sustainable change is possible. We believe that we are stronger when learning and leading together. We believe in the power of "small wins" and that anyoneat any age — can be an agent for change.

\section{References}

[1] National Science Foundation, "Women, Minorities, and Persons with Disabilities in Science and Engineering," National Science Foundation, National Center for Science and Engineering Statistics, Arlington, VA, 2015.

[2] S. Zweben and B. Bizot, “2014 Taulbee Survey,” Computing Research News, vol. 27, no. 5, pp. 2-51, 2015.

[3] C. Corbett and C. Hill, "Solving the equation: the variables for women's success in engineering and computing," American Association of University Women, Washington, DC, 2015.

[4] N. A. Fouad, and R. Singh, "Stemming the tide: Why women leave engineering," University of Wisconsin-Milwaukee, Milwaukee, WI, 2011.

[5] M. Klawe, T. Whitney, and C.Simard. "Women in Computing, Take 2", Communications of the $A C M$, vol. 52, no. 2, pp. 68-76. 2009.

[6] C. Simard, A. D. Henderson, S. K. Gilmartin, L. Schiebinger, and T. Whitney, "Climbing the technical ladder: Obstacles and solutions for mid-level women in technology," Michelle R. Clayman Institute for Gender Research at Stanford University, Anita Borg Institute for Women and Technology, 2008.

[7] J. Margolis and A. Fisher, Unlocking the Clubhouse: Women in Computing. MIT Press, 2003.

[8] S. Cheryan, V. C. Plaut, P. G. Davies, and C. M. Steele, "Ambient belonging: How stereotypical cues impact gender participation in computer science.," Journal of Personality and Social Psychology, vol. 97, no. 6, pp. 1045-1060, 2009.

[9] S. J. Correll, "Gender and the Career Choice Process: The Role of Biased Self-Assessments," American Journal of Sociology, vol. 106, no. 6, pp. 1691-1730, May 2001.

[10] S. J. Correll, "Constraints into Preferences: Gender, Status, and Emerging Career Aspirations," American Sociological Review, vol. 69, no. 1, pp. 93-113, Feb. 2004.

[11] C. Simard and S. Gilmartin, "Senior technical women: A profile of success," Anita Borg Institute for Women and Technology, Palo Alto, CA, 2010. 